\title{
0 negro na pré-história do trabalho assalariado
}

Anne Geraldi Pimentel ${ }^{1}$

Resumo: O objetivo deste trabalho é discutir a situação do negro na formação da classe operária brasileira. Para isso, recupero brevemente as condições sociais e econômicas em que viveram desde o período da escravidão. Sendo a construção da consciência de classe um fenômeno histórico, que se define na medida em que os homens vivem sua própria história, pensa-se que a classe operária brasileira, em sua formação, foi muito marcada pela diversidade étnica, ou seja, o negro e o imigrante tiveram seus papéis enquanto atores neste processo.

Palavras-chave: História, Negro, Trabalho Assalariado, Classe Operária Brasileira, Consciência de Classe.

Abstract: The objective of this paper is to describe the situation of the black workers during the formation of Brazilian working class. In order to do so, I briefly reflect on the economic and social conditions they have experienced since the slave trade era. Since building class conscience is a historical phenomenon, defined by people while they are living their own history, one can consider that the Brazilian working class, in the early stages of its development, was very influenced by its ethnic diversity.

Keywords: History, Black, Regulated Labour, Brazilian Working Class, Class Conscience.

\section{Introdução}

O objetivo deste trabalho é discutir a situação do negro na formação da classe operária. Assim, recupero brevemente, as condições sociais e econômicas em que viveram desde o período da escravidão. Além de detectar como os autores aqui citados trataram da questão do negro na formação do trabalho assalariado mo Brasil.

Para o desenvolvimento do texto escolhi dois autores principais, Paula Beiguelman e Florestan Fernandes. A primeira fez um estudo relacionado às

1 Mestranda em Ciências Jurídica e Sociais pelo Programa de Pós-Graduação em Sociologia e Direito da Universidade Federal Fluminense. Correio Eletrônico: hannah_agp@yahoo.com.br

cadernos cemarx, $\mathrm{n}^{\mathrm{o}} 5-2009 \quad 129$ 
implicações econômicas e políticas do sistema escravocrata no Brasil e uma breve incursão sobre a mudança da estrutura econômica; o segundo também se preocupa com o processo de transição de um sistema para outro, entretanto, o faz da perspectiva do negro enquanto indivíduo ou grupo. Isso torna interessante a contraposição entre estes dois autores, como complemento um do outro.

O estudo se justifica pelo fato de o negro compor a classe operária no Brasil. Considera-se o conceito de classe como um fenômeno histórico, definido pelos homens enquanto vivem sua própria história, no seu fazer-se, conforme Thompson (1987, p. 09), "a classe operária não surgiu tal como o sol numa hora determinada. Ela estava presente ao seu próprio fazer-se”. Assim, torna-se plenamente justificável pensar-se que a classe operária brasileira, em sua formação, foi muito marcada pela diversidade étnica. $\mathrm{O}$ negro e o imigrante tiveram seus papéis enquanto atores neste processo.

A partir do contexto de formação da classe operária brasileira, procura-se uma explicação para o porquê de Tarsila do Amaral, em seu quadro intitulado Operários, retratar um universo de operários no qual há poucos indivíduos da raça negra.

\section{O negro na formação da classe operária no Brasil}

É de grande importância o instituto da escravidão para o estudo do papel do negro na formação do trabalho assalariado no Brasil e, sobretudo, no que diz respeito ao período da industrialização em São Paulo.

O aumento da exploração da mão-de-obra escrava, no Brasil colônia, de acordo com Maria Sylvia de Carvalho Franco (1976, p. 10), está ligado ao aumento da produção de açúcar nos latifúndios. Afirma, também, que nesta fase (colonial) "a escravidão aparece como um "fator social construtivo", impulsionando a passagem de formas rudimentares para um tipo mais complexo de exploração econômica" (FRANCO, 1976, p. 12), principalmente na região de São Paulo.

Paula Beiguelman acredita que esta fase foi primordial para a acumulação capitalista pois, no seu entender, era o comércio dos negros que gerava o capital excedente, mas que com a Revolução Industrial, o sistema de produção pôde encontrar novas formas de trabalho, mais compensadoras. Contudo, segundo esta autora, a superprodução e a concentração da produção de açúcar no período posterior à extinção do tráfico envolvem uma "relação de indiferença", que "se traduz num processo que conduz à destruição do escravismo" (BEIGUELMAN, 1977, introdução). Isto porque antes mesmo da proibição do tráfico já existia um desinteresse dos proprietários de escravos, principalmente os da região norte-nordeste, na importação de mão-de-obra

130 O negro na pré-história do trabalho assalariado 
escrava, pois tinham interesse na valorização dos seus escravos, como forma de estabelecer um comércio dentro do território nacional (BEIGUELMAN, 1977, p. 04). Os proprietários do norte, cuja produção era essencialmente açucareira, tinham um excedente de mão-de-obra escrava e passaram a comercializá-los com os proprietários do sul e sudeste, onde a população negra havia diminuído seu contingente.

Desta forma, a posição dos proprietários de latifúndio não foi hegemônica com relação à extinção do tráfico de negros. Criou-se uma tensão entre os produtores do norte e do sul, por isso, conforme Beiguelman (1977, p. 06), a proibição do comércio de negros vindos da África, não teve a importância que lhe dão outros autores. Apesar disso, para o estudo que pretendo desenvolver, a questão da extinção do tráfico negreiro é bastante importante, já que um dos seus reflexos foi a transferência da população negra da zona açucareira para o sudeste, zona cafeeira, tendo como conseqüência o equilíbrio desta população no território nacional.

Além da extinção do comércio de negros trazidos da África, outro fator deve ser considerado na análise da diminuição da população negra no Brasil: as péssimas condições de vida que levavam, tanto durante a escravidão como após a abolição.

Falta de higiene, promiscuidade (que levava à proliferação de doenças venéreas), epidemias, verminoses, lepra são alguns dos motivos dos altos índices de mortalidade entre os negros no período da escravidão, como aponta Emília Viotti da Costa (1982). Por outro lado, conforme a mesma autora, a taxa de natalidade permanecia em índices muito baixos, devido não só ao número muito reduzido de mulheres, mas também ao alto índice de mortalidade infantil.

Entretanto, Viotti (1982, p. 248 - 249) alerta para o problema de se avaliar a situação real dos negros antes da abolição: apesar da população escrava ter diminuído durante o século XIX, pode ter havido uma melhora nas condições de vida do escravo e, com isso, uma redução da mortalidade. Mas as condições de vida não aparecem nos cálculos sobre da mortalidade porque, devido aos altos preços e às dificuldades de compra de escravos, os proprietários tinham interesse em subtraí-los da fiscalização oficial. Por outro lado, as alforrias dificultavam o cálculo da mortalidade entre os negros.

Ao lado da discussão sobre a diminuição progressiva da população negra, cujos reflexos aparecerão mais tarde e, principalmente em São Paulo, está o problema da situação dos negros libertos, ainda no período anterior à abolição, devido a Lei do Ventre Livre e às alforrias. Uma parte muito ínfima desta população se manteve no

cadernos cemarx, $\mathrm{n}^{\mathrm{O}} 5-2009 \quad 131$ 
trabalho rural, essencialmente na área cafeeira; mas, em outras partes, o trabalho do liberto foi sobrepujado pelo trabalho do imigrante. Beiguelman entende que esta seja a explicação para o fato dos negros libertos procurarem as áreas urbanas:

As reservas de trabalho livre e liberto na área rural já eram suficientes para atender às necessidades da grande lavoura que, no setor de vanguarda, se supria de braço italiano. Essa, talvez, a explicação estrutural para o fato de ter uma parte do elemento liberto desempregado (com capacidade ociosa, pois) - ao invés de intenta-se pelo mato (exercendo uma agricultura de subsistência) - demandado os núcleos urbanos onde, agravados pela questão específica do preconceito de cor, permaneceu em situação de marginalismo e anomia (BEIGUELMAN, 1977, p. 115).

Os centros urbanos mais procurados por estes libertos foram Recife, Salvador, Rio de Janeiro e São Paulo. Embora, conforme Florestan Fernandes (1978, p. 1819), cujo estudo se voltou especificamente para São Paulo, cidade na qual os negros libertos enfrentaram influências diversamente negativas das encontradas nas outras. Resumidamente, são três os pontos: inclusão tardia na economia de exportação local, o que não produziu oportunidades de trabalho; competição com o imigrante europeu; a concepção tradicionalista do mundo e a dominação patrimonialista dos paulistanos, com o predomínio do pensamento liberal econômico. Nesta ordem, somente os negros submissos ou que eram protegidos encontravam alguma acolhida.

O aumento da população de São Paulo no fim do século XIX deveu-se mais à população imigrante - que vinha para trabalhar nas zonas rurais, mas que migrava para os centros urbanos em busca de melhores oportunidades - do que a nacional, formada pelos brancos e por negros e mulatos (FERNANDES, 1978, p. 63). Assim, entendo que a diminuição da população negra aparece, na verdade, em termos relativos, mas nem tanto em termos absolutos. Eram intensas as imigrações no último quarto do século XIX e início do XX, inclusive com subsídio do governo (BEIGUELMAN, 1977, p. 24 e 66), o que tornava a mão-de-obra imigrante mais barata. A meu ver, essa foi a causa não só da população global ter aumentado, como também do aumento da desproporção entre brancos imigrantes europeus e os nacionais (brancos, negros e mulatos).

Florestan Fernandes aponta para a diminuição da população global de negros e mulatos no final do século XIX, atribuindo-a às péssimas condições de vida, que levavam a altas taxas de mortalidade, entre adultos e crianças. Entretanto,

132 O negro na pré-história do trabalho assalariado 
diferentemente de alguns autores, que alegavam que este fenômeno se devia à inferioridade da raça, Fernandes considera que estas condições de vida e os altos índices de mortalidade não eram exclusividade dos negros,

Todavia, para determinar-se, conclusivamente, a influência tópica das condições econômicas, sociais e culturais de existência do negro e do mulato, no quadro dessas doenças, bem como para presumir a propensão deles à aquisição de determinada moléstia contagiosa, seria preciso fazer levantamentos estatísticos que levassem em conta longos períodos e favorecessem a focalização explícita rigorosa dos fatores sócio-culturais ou econômicos, a serem testados objetivamente. Aliás, se confrontássemos indivíduos 'brancos', 'mulatos' e 'negros' de populações relativamente homogêneas, veríamos que há ampla margem para especulações inversas, fundadas na resistência dos dois últimos às condições desfavoráveis do ambiente, inclusive às moléstias contagiosas (FERNANDES, 1978, p. 101).

Estas condições empurravam os negros para um enfrentamento com os imigrantes, já que foram "excluídos ou se excluíram da ordem legalmente institucionalizada da sociedade nacional", impelidos pelas condições "econômicas, psicossociais e sócio-culturais", como Fernandes (1978, p. 60) desenvolve em seu livro. Diante disso, os imigrantes conseguiam absorver as melhores oportunidades de trabalho livre.

Nas ponderações de Beiguelman, que também trata do assunto:

O imigrante, como um todo, se apresentava, com respeito ao nacional, como um açambarcador das novas oportunidades econômicas, mais ou menos vantajosas, que dispensassem capital inicial - além de penetrar nos setores tradicionais (BEIGUELMAN, 1977, p. 119).

Interessante é a diferença destes autores quando tratam da questão do branco nacional e do negro. A composição do elemento nacional, para Beiguelman, engloba tanto os brancos como os negros, que são tratados como um bloco, sem levar em conta que mesmo neste grupo há contradições. Fernandes se posiciona da maneira diversa, pois argumenta que os afro-descendentes estão em disputa não somente com o branco estrangeiro, mas também com o branco nacional. A partir desta referência, concluo que os negros e os mulatos nacionais; os brancos nacionais; e os brancos estrangeiros formam três grupos distintos que se confrontam e que o primeiro grupo

cadernos cemarx, $\mathrm{n}^{\circ} 5-2009 \quad 133$ 
está em desvantagem por causa das condições em que vivia, sendo empurrado para a pior situação na estrutura econômica.

$\mathrm{Na}$ medida em que não estavam incorporados ou se incorporavam apenas parcialmente ao sistema de classes emergente, o negro e o mulato viviam numa situação ambígua, em confronto com os brancos nacionais e estrangeiros (FERNANDES, 1978, p. 156).

Segundo Fernandes, a desorganização social em que viviam os afrodescendentes os levou a uma situação de pauperismo e anomia social. Alguns aspectos das condições sócio-culturais que o autor cita são: a falta de solidariedade familiar; a desestrutura familiar; o alcoolismo; a prostituição; e a criminalidade. Beiguelman (1977, p. 115) também menciona este estado de anomia social a que o negro se condicionou ou foi condicionado.

Juntamente com este tema estão as condições psicossociais que os afrodescendentes tiveram como herança da escravidão. "No nível psicológico, o negro e o mulato viam-se impossibilitados de ajustar suas atitudes, seu comportamento e sua personalidade aos requisitos psicossociais da 'sociedade competitiva"' (FERNANDES, 1978, p. 225).

A espoliação dos negros, durante a escravidão, foi material e moral: eram obrigados a se sujeitar a trabalhos degradantes, à submissão aos seus proprietários, não tinham nenhum poder sobre suas vidas. Nestas condições, quando se viam libertados destes grilhões, alguns ficavam nas zonas rurais e viviam de suas lavouras de subsistência. Entretanto, alguns deles, como mencionado acima, procuravam os grandes centros urbanos, onde encontravam não só um ambiente desfavorável, mas também encontravam o conflito do indivíduo com a emergente sociedade de classes e que os conduziram a um confronto direto com os imigrantes.

Um primeiro problema foi a recusa dos libertos a se sujeitarem a trabalhos que os lembrassem de sua antiga condição. Segundo Fernandes (1978, p. 29), o que lhes importava "era a condição moral da pessoa e sua liberdade de decidir como, quando e onde trabalhar". Acreditavam que era através do trabalho (assalariado) que provariam "a dignidade e a liberdade de pessoa humana; por isso, recusavam certas tarefas e o controle sobre o seu tempo". Já os imigrantes europeus, que vieram "fazer a América", aceitavam qualquer condição de trabalho, pois viam isso como um início de uma nova vida. Assim, "o liberto defrontou-se com a competição do imigrante

134 O negro na pré-história do trabalho assalariado 
europeu, que não temia a degradação pelo confronto com o negro e absorveu, assim, as melhores oportunidades de trabalho livre e independente" (FERNANDES, 1978, p. 19).

Outro problema, que também está relacionado com o confronto entre o negro e o imigrante, foi que este último foi considerado o "agente natural para o trabalho livre" (FERNANDES, 1978, p. 27), ou seja, foi construída uma imagem estereotipada da mão-de-obra estrangeira como superior à nacional. A maioria dos autores percebe $\mathrm{e}$ faz referência a este assunto, todavia, cada um a partir de uma perspectiva diferente.

Quando Beiguelman descreve a composição demográfica do trabalho urbano observa que, para alguns autores, a pouca participação do negro no começo da industrialização de São Paulo se deve à inferioridade da habilitação do elemento nacional em relação à mão-de-obra estrangeira. Para ela, diferentemente, isto aconteceu devido ao reduzido contingente do elemento nacional na população, devendo-se lembrar que, na concepção da autora, este grupo é formado por brancos livres e os negros.

A quase ausência do elemento nacional na indústria de São Paulo no período de sua formação, tem conduzido alguns autores a concluir por uma habilitação superior da mãode-obra estrangeira, suposta superioridade esta que é elevada, inclusive, à categoria de fator favorável no desenvolvimento de uma indústria para a qual o braço nacional, livre ou escravo, se teria revelado incompetente (BEIGUELMAN, 1977, p. 122).

Porém, esta parece ser um analise bastante simplista, posto que embora seja fato que a população de brancos estrangeiros era muito maior do que a de negros, a autora infere em erro ao crer que só por esse motivo os negros não fizeram parte da mão-de-obra nas indústrias. $O$ preconceito em relação ao negro e a suposição de que o imigrante europeu seria dotado de maior qualificação, sendo portanto o "agente natural para o trabalho assalariado", fizeram com que o negro entrasse em desvantagem com o imigrante na concorrência pelas ocupações nas fábricas.

Beiguelman comprova, por meio de depoimentos, que o elemento nacional possuía habilidade para o ofício de artesão, e cita até experiência de uma fábrica têxtil ao empregar a mão-de-obra escrava. A diferença entre o negro e o branco estrangeiro não era biológica. Uma vez que os dois possuem capacidades iguais para o trabalho, o que se discute, na verdade, é a concepção de um preconceito socialmente construído. No processo de mudanças econômicas, sociais e culturais de uma sociedade escravista

cadernos cemarx, $\mathrm{n}^{\mathrm{0}} 5-2009 \quad 135$ 
para a capitalista, o negro sofreu as piores conseqüências, foi condenado, bem como se condenou, ao aviltamento de sua condição como potencial agente do trabalho livre:

Sem as garantias de reparações materiais e morais escrupulosas, justas e eficazes, a Abolição equivalia - nas zonas de vitalidade da lavoura cafeeira - a condená-lo à eliminação no mercado competitivo de trabalho ou, no mínimo, ao aviltamento de sua condição, como agente potencial de trabalho livre. Longe de equipará-lo ao trabalhador assalariado branco, estrangeiro ou nacional, expunha-o fatalmente, de modo previsível e insanável, ao desajustamento econômico, à regressão ocupacional e ao desequilíbrio social (FERNANDES, 1978, p. 43).

É possível perceber, portanto que, no processo de urbanização e industrialização, principalmente na cidade de São Paulo, os negros ficaram à margem das oportunidades deste sistema ocupacional. Para sobreviverem, aceitavam empregos domésticos, mal remunerados e que exigiam pouca qualificação. Segundo um informante citado por Fernandes, esses eram considerados "serviços de negros" (FERNANDES, 1978, p. 142).

Com o fim da imigração, entre as décadas de 30 e 40, já no governo de Getúlio Vargas, a situação do negro na estrutura econômica parece melhorar. Florestan Fernandes (1978, p. 157) argumenta que a escassez de mão-de-obra, causada pela interrupção da vinda dos imigrantes europeus, contribuiu para a aceitação dos negros no mercado de trabalho assalariado. Beiguelman também faz referência ao aumento do emprego da mão-de-obra do elemento nacional na indústria "à medida que, vagando-se as posições ou ampliando-se esses quadros, se veja intensamente solicitado" (BEIGUELMAN, 1977, p. 123). Entretanto, não é possível distinguir a situação do negro, porque a autora engloba no mesmo grupo (o elemento nacional) os brancos livres e os negros, como já se disse anteriormente. Este, contudo, não é o tema deste texto, assim deixo somente a menção ao problema.

Assim, com o fim da escravidão, que liberou um contingente de trabalhadores livres (despossuídos dos meios de produção e do fruto de seu próprio trabalho), e a com emergência de uma sociedade de classes, o negro foi relegado às camadas mais miseráveis. Segundo Fernandes (1978), trata-se de um processo de desorganização da estrutura sócio-econômica e de pauperização da população negra no período de formação do sistema de produção capitalista no Brasil.

A meu ver, esse período corresponde à acumulação capitalista primitiva

\begin{tabular}{l|l}
136 & O negro na pré-história do trabalho assalariado
\end{tabular} 
(MARX, 2001, p. 827 sgs.), ou seja, à origem histórica do capital dada pela expropriação dos produtores diretos ou pela transformação direta de escravos em assalariados, para criar uma massa humana de destituídos dos meios de sobrevivência e jogadas no mercado de trabalho sem qualquer direito. No Brasil, esta massa humana foi formada, em sua maior parte, pela grande quantidade de imigração, ocorrida durante o fim do século XIX e início do XX; em uma parcela menor, pelos pequenos proprietários de terras que foram expropriados; e, pelos negros escravos transformados em trabalhadores livres.

Mas há, no Brasil, certas peculiaridades no processo de formação do sistema capitalista. Isto porque, a partir das discussões feitas até o momento neste texto, entendo que, desde a extinção do tráfico até a abolição, a população negra empobrecida e apática foi condenada a formar um excedente de mão-de-obra. Para Fernandes, dentro da estrutura econômica brasileira, onde havia maior produção combinada com crescimento econômico e organização do trabalho, os negros "constituíam um verdadeiro exército de reserva" (FERNANDES, 1978, p. 17) quando concorriam com os trabalhadores nacionais e, principalmente, com os imigrantes.

Estranho é que na literatura sobre a história da formação do sistema de produção capitalista no Brasil, principalmente nos autores da década de 60 e 70, a situação do negro seja tomada de forma bastante periférica. Paula Beiguelman se enquadra neste padrão, pois se refere ao negro de forma superficial. Apesar de dedicar boa parte de seus estudos sobre a formação do povo no complexo cafeeiro à questão do comércio de negros e à abolição, engloba o trabalho do homem livre e do liberto na mesma categoria, ignorando, desta forma, as características peculiares de cada grupo que compõe este elemento nacional, conforme sua denominação.

Faço menção a outros autores como Boris Fausto e Sheldon Maran. O primeiro trabalha a composição étnica como determinação estrutural, que "incidiu contraditoriamente no comportamento operário em geral e nas concepções ideológicas dos setores organizados da classe" (FAUSTO, 2000, p. 29), O tema da etnia a que o autor se refere está envolto no problema da nacionalidade, remete à disputa entre os estrangeiros e os nacionais, assim não distingue, a exemplo de Beiguelman, a situação específica do negro. O segundo, da mesma maneira, quando fala sobre os brasileiros também não faz distinção entre os homens brancos livres e os negros (MARAM, 1977, p. 178-210).

cadernos cemarx, $\mathrm{n}^{\mathrm{o}} 5-2009 \quad 137$ 


\section{Conclusão}

Todo o processo histórico do Brasil, desde o comércio de negros e sua extinção; a vinda dos imigrantes, tanto europeus como asiáticos, foram instrumentos que alavancaram e estimularam a acumulação capitalista e que, progressivamente, deu forma ao sistema capitalista de produção.

O comércio de negros estimulou o que se pode chamar de acumulação primitiva do capital, ou seja, gerou um excedente de capital, bem como a exploração da mão-de-obra dos escravos. Apesar de que, mesmo com a Abolição, o negro continuou a ser explorado, houve uma mudança na forma da exploração.

As imigrações também foram um fator que colaborou com a expansão do capital.

Os imigrantes vieram para trabalhar nas fazendas, principalmente nas de café, mas uma parte deles migrou para os centros urbanos, principalmente São Paulo, em busca de melhores oportunidades para "fazer a América". Sua presença aumentou a concorrência no mercado de trabalho, afastando dos negros qualquer possibilidade de se situar melhor na estrutura econômica.

Devido às suas condições psicossociais e culturais, o negro se conduziu e foi conduzido a um estado de pauperização e anomia social. Esteve, no período pré-capitalista, à margem da sociedade, e aqui também foram instrumentos do capital, pois formaram uma população excedente (exército de reserva), necessária ao desenvolvimento da riqueza no sistema capitalista.

Interessante é que a pouca presença do negro nesta época está representada na tela Operários, de Tarsila do Amaral, artista modernista do começo do século e que esteve presente na semana de arte moderna de 1922, um grande marco na história da arte no Brasil. Neste quadro, o universo dos trabalhadores está representado, ao fundo, pelas chaminés das fábricas, e numa perspectiva ampla estão os trabalhadores, cerca de cinqüenta rostos que mostram uma grande diversidade étnica, mas somente quatro deles (menos de dez por cento) possuem características da raça negra.

\section{Bibliografia}

BEIGUELMAN, Paula. A Formação do povo no complexo cafeeiro. $2^{\mathrm{a}}$ ed. São Paulo: Pioneira, 1977.

FAUSTO, Boris. Trabalho urbano e conflito social. $5^{\mathrm{a}}$ ed. Rio de Janeiro: Bertand Brasil, 2000.

FERNANDES, Florestan. A Integração do negro na sociedade de classes. $3^{\mathrm{a}}$ ed. São

138 O negro na pré-história do trabalho assalariado 
Paulo: Ática, 1978, vol 1.

FRANCO, M. S. C. Homens livres na ordem escravocrata. São Paulo: Ática, 1976.

MARAM, S. L. "The immigrant and the Brazilian labor moviment, 1890 - 1920". In: A. Dauril e W. Dean (Eds.), Essays concerning the socioeconomic history of Brazil and Portuguese Índia. Gainesville, University Presses of Florida, p. 178-210, 1977.

MARX, Karl. O Capital: crítica da economia política: livro I, vol 2. Tradução de Reginaldo Sant'anna. - 17 ed. - Rio de Janeiro: Civilização Brasileira, 2001.

THOMPSON, E. P.. A Formação da classe operária inglesa. Trad. Renato Busatto Neto, Cláudia Rocha de Almeida. Rio de Janeiro: Paz e Terra, 1987.

VIOTTI DA COSTA, E. Da Senzala à colônia. $2^{\mathrm{a}}$ ed. São Paulo: Livraria Editora Ciências Humanas Ltda., 1982.

cadernos cemarx, $\mathrm{n}^{\circ} 5-2009 \quad 139$ 